\title{
THE BRITISH EXPERIENCE WITH HEROIN REGULATION
}

\author{
Trevor BennetT* \\ I \\ INTRODUCTION
}

Heroin and other opioid ${ }^{1}$ regulation in Britain is more complex now than it has ever been. Opium was first introduced into Britain during the tenth and eleventh centuries. ${ }^{2}$ From that time until the early nineteenth century there was no formal control of opium or opium-based products. Regulation in the nineteenth century was limited to the passing of one Act of Parliament which specified the conditions for the sale of Arsenic (Arsenic Act 1851) ${ }^{3}$ and another which limited the sale of certain drugs to pharmacists (Pharmacy Act 1868). ${ }^{4}$ The early years of the twentieth century witnessed a spate of parliamentary activity which resulted in the enactment of two acts limiting the supply of certain drugs to prescription by a doctor in the course of medical treatment. ${ }^{5}$ This legislative activity halted abruptly in 1926 following the publication of the Report of the Departmental Committee on Morphine and Heroin Addiction (the Rolleston Committee Report) ${ }^{6}$ which heralded a period of nearly forty years of tranquillity in Britain, known as the Rolleston Era. ${ }^{7}$ During this period, the medical profession regulated the distribution of licit opioid supplies and the provisions of the Dangerous Drugs Acts of 1920 and 1923 controlled illicit supplies. ${ }^{8}$

During the 1950's, a small increase in illegal drug use in Britain stimulated a process of rapid policy reconsideration and change which has continued unabated to the present day. Because of this change, a complicated web of legal and medical constraints, treatment methods, and information controls

\footnotetext{
Copyright (C) 1988 by Law and Contemporary Problems

Senior Research Associate, Institute of Criminolgy, Cambridge, England.

1. The currently accepted word in Britain to describe opium-based and opium-like drugs is the single term "opioids." The word "opioids" is used in this paper in preference to the North American term "opiates." Because of the inelegance of both words and because neither are well known outside of the medical and social science professions, the paper will sometimes refer to the single drug heroin (as in the title) unless the context demands greater precision.

2. V. Berridge \& G. Edward, Opium and the People xxiii (1981).

3. The Arsenic Act, 1851,14 \& 15 Vict. ch. 13.

4. The Pharmacy Act, 1868, 31 \& 32 Vict. ch. 121.

5. Dangerous Drugs Act, 1920, 10 \& 11 Geo. 5, ch. 46. Dangerous Drugs and Poisons (amendment) Act, 1923, $13 \& 14$ Geo. 5, c. 5.

6. See generally Departmental Committee on Morphine and Heroin Addiction, Report (1926) [hereinafter ROLLESTON COMMITTEE REPORT].

7. A. Trebach, The Heroin Solution 84 (1982).

8. Dangerous Drugs Act, 1920, supra note 5; Dangerous Drugs and Poisons (amendment) Act, 1923 , supra note 5 .
} 
has evolved. Drugs policy has become so complex that "the task of policy commentary is more complicated (now) than at any other period in the history of British drugs policies". 9

The aim of this article is to describe and explain the system of opioid regulation in Britain. In particular, the author seeks to identify some of the recent developments in drugs policy and to analyze their underlying themes. The purpose of exploring the key elements of the British approach to heroin regulation is not only to suggest future directions for drugs policy in Britain, but also to provide a useful comparison for policy analysts and policy makers in other countries.

\section{II}

\section{The British System}

The meaning of the term "British System," or "British Approach," is not completely clear. It is most frequently used to describe the years of stability and tranquillity following the publication of the Rolleston Committee Report. The term "system" was first used in 1937 by E.W. Adams, who had served on the Rolleston Committee, ${ }^{10}$ and later was developed by Edwin Schur (1963), ${ }^{11}$ Alfred Lindesmith (1965), ${ }^{12}$ and Horace Judson (1974). ${ }^{13}$ The term is also used to refer to more recent periods in the evolution of British policy. ${ }^{14} \mathrm{~A}$ major problem with the concept, which weakens its usefulness, is that the word "system" is perhaps too strong, as it connotes organization, planning, and directives. In contrast, British drugs policy has actually evolved out of practice rather than planning and tends to be directed only by loose guidelines. ${ }^{15}$

It is clear that the British Approach, whether or not it is a system, is unique in that doctors are willing to define addiction as an illness and to prescribe opioids to addicts. In the following section the British System, which covers the period from 1926 to the present, is defined in this broader sense. There are three distinct phases that delineate the development of this system: The first is the Rolleston Era which began with the Report of the Departmental Committee on Morphine and Heroin Addiction in 1926 and lasted relatively

9. Stimson, British Drug Policies in the 1980's; A Preliminary Analysis and Suggestions for Research, 82 Brit. J. Addiction 477, 485 (1987).

10. The Rolleston Committee is the Departmental Committee on Morphine and Heroin Addiction chaired by Sir Humphrey Rolleston, which produced the influential Rolesston COMMITTEE RePORT.

11. See generally E. Shur, Narcotic Addition in Britain and America (1963).

12. See generally A. Lindesmith, The Addict and the Law (1965).

13. See generally H. Judson, Heroin Addiction in Britain (1974).

14. See Edwards, Some Years On: Evolutions in the "British Systems," in Problems of Drug ABuse in Britain 1 (D. West ed. 1978).

15. See Smart, Social Policy and Drug Addiction: A Critical Study of Policy Development, 79 BRIT. J. Addiction 31-39 (1984). Smart concludes that "it would seem that the establishment of specially designated clinics in the 1960's was not grounded in the new ideas of the times which argued for treatment in place of punishment. Rather, this development can be linked with the growth of rational scientific knowledge which made possible new technologies which were not available to policy makers in the nineteenth and twentieth centuries." Id. at 38 . 
unchanged until the early 1960's; ${ }^{16}$ the second comprises the period of change and re-appraisal leading to the two Brain Committee Reports in 1961 and 1965 and the establishment of the Clinic System in 1968; ${ }^{17}$ and the third is the present period characterized by a decline in the prominence of the clinic and the growth of a more diverse system of treatment and control during the 1970 's and 1980's. ${ }^{18}$

\section{A. The Rolleston Era}

The British System originated with the publication of the Rolleston Committee Report in 1926. Before this date there was scant medical and legal control over the use of dangerous drugs and no coherent national strategy for dealing with drug addiction as a social or individual problem. The 1920 Dangerous Drugs Act ${ }^{19}$ permitted doctors to prescribe dangerous drugs for medical treatment only. This gave them the right to prescribe controlled drugs to addicts if they thought that such was medically beneficial. ${ }^{20}$ At the time, the problem of drug addiction was not a top priority for the government. Eventually, however, the Home Office ${ }^{21}$ became concerned about whether prescribing controlled drugs to addicts constituted proper medical treatment as defined under the 1920 Act.

The issue of the right of doctors to prescribe addictive drugs was presented to a departmental committee under the chair of Sir Humphrey Rolleston, the British Minister of Health. The committee's mandate was:

to consider and advise as to the circumstances, if any, in which the supply of morphine and heroin (including preparations containing morphine and heroin) to persons suffering from addiction to those drugs may be regarded as medically advisable, and as to the precautions which it is desirable that medical practitioners administering or prescribing morphine or heroin should adopt for the avoidance of abuse, and to suggest any administrative measures that seem expedient for securing observance of such precautions. ${ }^{22}$

The report of the Rolleston Committee concluded that prescribing heroin and morphine to addicts was a legitimate medical treatment for addicts who were (1) under treatment by the gradual reduction method and (2) suitable for indefinite and prolonged administration of the drugs. ${ }^{23}$ The report identified two classes of addicts that were suitable for "indefinitely prolonged administration" of heroin or morphine:

16. See generally Spear, British Experience in the Management of Opiate Dependence, in ThE DEPENDENCE Phenomenon 52 (M. Glatt \& J. Marks eds. 1982).

17. Id.

18. Id.

19. Dangerous Drugs Act, 1920, supra note 5.

20. Id.

21. The Home Office is a government department headed by the Home Secretary which is responsible for internal affairs. Among the responsibilities of the Home Office is monitoring the sale and distribution of dangerous drugs.

22. Rolleston Committee Report, supra note 6 , at 3.

23. Id. at 18 . 
(a) Those in whom a complete withdrawal of morphine or heroin produces serious symptoms which cannot be treated satisfactorily under the ordinary conditions of private practice; and

(b) Those who are capable of leading a fairly normal and useful life so long as they take a certain quantity, usually small, of their drug of addiction, but not otherwise. ${ }^{24}$

The Rolleston Committee Report thus reaffirmed the disease model of addiction and placed the treatment and control of addiction firmly in the hands of the medical profession. ${ }^{25}$

The recommendations of the Rolleston Committee Report, which were incorporated into the Dangerous Drugs Regulations of $1926,{ }^{26}$ formed the basis of British policy for the next four decades. With the exception of the enactment of the Pharmacy and Poisons Act of $1933,{ }^{27}$ which established rules and procedures relating to the security and distribution of dangerous drugs, the British drugs policy remained unchanged until the 1960's.

As applied to the Rolleston Era, the term British System may be a misnomer because of the limited level of control and influence exerted by either the Home Office or the medical profession. ${ }^{28}$ Some have argued that the British medical approach prevented a drug problem because it enabled addicts to obtain medical help and to obtain licit supplies of the drugs to which they were addicted. ${ }^{29}$ The extent to which the Rolleston system contained the spread of addiction is unclear.

Evidence from prosecutions and convictions for drug offenses relating to opium and Home Office Drugs Branch statistics on the number of known addicts indicate little usage of dangerous drugs in the country from the time of the Rolleston Report to the mid-1950's. ${ }^{30}$ Other than one or two peaks over the forty year period, the pattern of opium prosecutions and convictions remained fairly constant. In the year following the implementation of the 1920 Act, there were 184 prosecutions for opium offenses. ${ }^{31}$ This number fell to under fifty in 1924 and remained at this level until it rose in 1941 to 201 and remained high until 1945. ${ }^{32}$ This temporary increase was due to a

24. Id.

25. "There was general agreement that in most well-established cases, the condition must be regarded as a manifestation of disease and not as a mere form of vicious indulgence. In other words, the drug is taken in such cases not for the purpose of obtaining positive pleasure, but in order to relieve a morbid and overpowering craving." Id. at 11 .

26. Dangerous Drugs Regulations, S.I. 1926, No. 996. See G. Stimson \& E. Oppenheimer, Heroin addiction: Treatment and Control in Britain 31 (1983).

27. The Pharmacy and Poisons Act, 1933, 23 \& 24 Geo. 5, ch. 25.

28. Control was limited during the first half of the twentieth century because doctors were allowed almost complete discretion in deciding who should be prescribed opioids and the length and nature of the prescription. There were few formal or informal guidelines which served to limit the discretion of individual doctors in determining the way in which they should treat their addict patients.

29. See, e.g., E. SHuR, supra note 11.

30. This evidence and statistical data is reported in Spear, The Growth of Heroin Addiction in the United Kingdom, 64 BRIT. J. Addiction 245, 245-55 (1969). From 1921-1953 inclusive, official figures for criminal proceedings relate to prosecutions and from 1954 to the present, official figures relate to convictions. Id. at 246 .

31. Id. at 246 .

32. Id. at 245 . 
combination of an increase in police enforcement, an increase in the number of Chinese seaman in British cities, and changes in the shipping routes of opium from India during the war. ${ }^{33}$ After World War II, the annual number of prosecutions and convictions fell to under 100 and remained at that level until well into the 1960's. ${ }^{34}$

Figures on the number of known British opium addicts have been published by Bing Spear, former Chief Inspector of the Home Office Drugs Branch. He reported that in 1935, the year following the establishment of the Drugs Branch, there were approximately 700 addicts known to the Home Office and in 1936, the first full year of recording, the total stood at $616 .^{35}$ After 1937, the number of known addicts declined yearly to a low of 290 in $1953 .^{36}$ During this time, the number of addicts in the country was so small that the Home Office was able to keep itself informed about the personal life and history of each addict. ${ }^{37}$

The characteristics of the addicts of the 1930's, 1940's, and early 1950's differ markedly from those of current addicts. Until the early 1960's, most known addicts were addicted to morphine, and it was not until 1962 that the number of heroin addicts surpassed the number of morphine addicts. ${ }^{38}$ The early dominance of morphine was in part due to the high number of "professional addicts"- - Home Office term referring to doctors, dentists, and pharmacists who had direct access to morphine. During the 1930's and 1940 's, between one-quarter and one-fifth of all addicts fell into this category. ${ }^{39}$ Others addicted to morphine were called therapeutic addicts: people who became addicted due to morphine treatment for their illnesses. Although there are no early figures available on the proportion of therapeutic addicts, it is believed that prior to World War I the majority of cases of addiction were therapeutic in origin. ${ }^{40}$

While the statistical evidence shows that the level of addiction in Britain was low and fairly stable during the years following the Rolleston Report, ${ }^{41}$ there is little to suggest that this resulted directly from British policy to medicalize rather than criminalize addiction. First, it is implausible that the number of therapeutic addicts could be diminished by a policy of prescribing drugs to addicts. In fact, such a policy could just as easily lead to an increase

33. Id. at 246 .

34. Id. at 247 .

35. Id. Addicts known to the Home Office Drugs Branch were initially identifed from routine police inspections of pharmacists' records of prescriptions dispensed for dangerous drugs and from information received from the police and prisons. More recently, addicts become known to the Home Office through a system of formal notification.

36. Id. at 252.

37. See G. Stimson \& E. Oppenheimer, supra note 26, at 34. This observation was also confirmed in a personal communication with Spear who believed that for some considerable time he was able to recall the names of most of the addicts in the country from memory.

38. See Spear, supra note 30 , at 245.

39. Id. at $\mathbf{2 4 8 .}$

40. Figures for the years covering 1954-1959 show that about one-third of all known heroin addicts became addicted as a result of treatment for other illnesses. Id. at 250 .

41. Id. at 245-51. 
in therapeutic addicts by making heroin and other opioids available and more acceptable in the treatment of diseases, and by making addiction longer lasting through a policy of long term prescription of addictive drugs. Second, it is unlikely that the number of professional addicts could have been decreased by a policy of medicalization. Again, it seems just as likely that such a policy could increase the number of professional addicts by making opioids more accessible and by eliminating a possible penal deterrent which would have accompanied the alternative policy of criminalization. Third, there is no aspect of the Rolleston approach that would account for the consistently low demand for recreational use of opioids. Until the 1950's, recreational morphine or heroin use was confined to small "artistic" groups and to isolated Chinese communities. ${ }^{42}$ Finally, it is difficult to argue that it was the British System that contained addiction during the 1930's, 1940's, and 1950's when in the 1960's addiction rose dramatically under the identical system of regulation.

\section{B. The Clinic Era}

In the late 1940's, the first signs of change occurred which heralded the demise of the Rolleston Era and began a process which led to the emergence of the Clinic System in 1968. Until the 1950's it was believed that marijuana use was confined to a small number of Negro groups in London. ${ }^{43}$ In 1950 , however, British authorities discovered that imported marijuana was being used for recreational purposes by members of the general public.44 A raid by the Metropolitan Police on a jazz club in the West End of London revealed that ten of the approximately 250 persons at the club were in possession of marijuana and three were in possession of cocaine. ${ }^{45}$ Nine of the ten men in possession of marijuana were white. ${ }^{46}$ In addition, twenty-three packets of marijuana, one pack of cocaine, an empty morphine ampule, and a small quantity of prepared opium were found on the floor of the club. ${ }^{47}$ The raid revealed recreational use of marijuana and opioids among the white population and that the average drug user was younger than before. ${ }^{48}$ Further discoveries and seizures during the early 1950's confirmed a broadbased change in the nature of addiction in Britain and signalled the emergence of a new drug subculture.

In June of 1958, the Ministry of Health set up an interdepartmental committee, chaired by Sir Russell Brain, to reappraise the recommendations of the Rolleston Committee. The Brain Committee reaffirmed that addiction was a medical matter and continued to support the Rolleston

42. See G. Stimson \& E. Oppenheimer, supra note 26 , at 32.

43. Id. at 39 .

44. Id.

45. The details of this raid are reported in chapter two of G. STIMson \& E. OPPEnHEIMER, supra note 26 , at $38-39$.

46. Id. at 39 .

47. Id. at $38-39$.

48. Id. at 39 . 
recommendations. It found no evidence of any actual increase in the recreational use of drugs. ${ }^{49}$

Between 1961, the year of publication of the Committee's report, and 1965 , further changes occurred in the British drug scene. Young people from a wide range of social backgrounds began using amphetamines, LSD, marijuana, cocaine, and opioids. ${ }^{50}$ In 1962, for the first time, the number of persons addicted to heroin exceeded the number addicted to morphine. ${ }^{51}$ In addition, a few private practitioners began to prescribe heroin in large quantities. One of these private doctors was Lady Frankau of Wimpole Street who prescribed to over 50 addicts, some of whom received 1800 milligrams of heroin a day (about 180 times the therapeutic dose). ${ }^{52}$ Doctors prescribed very high dosages to hundreds of street addicts in London, who in turn sold part of their prescriptions, creating a "grey" market ${ }^{53}$ in pharmaceutical heroin. ${ }^{54}$ Between 1955 and 1965, the number of addicts known to the Home Office increased threefold. ${ }^{55}$ In response to these developments, the Brain Committee was asked on July 30,1964 , to reconvene.

The Brain Committee opined that the two main elements of the problem were the growing number of addicts and the over-prescribing by a small number of private doctors. It proposed, therefore, to address not only the problem of the addicts, but also the problem of the doctors. The Second Brain Committee Report concluded that addiction was still a medical matter, and the Brain Committee thus continued to endorse the disease model and a medical response. ${ }^{56}$

The Brain Committee made three recommendations for tackling addiction. First, only doctors licensed by the Home Secretary should be authorized to supply heroin and cocaine to addicts. Second, specialized drug treatment centers should be created from which licensed doctors would be able to prescribe drugs of addiction to addicts. Third, a system of notification of addicts should be implemented. The effect of these proposals was to create a system, administered by the medical profession, whose twin aims were treatment and control. The Brain Committee's proposals were enacted by the Dangerous Drugs Act of 1967,57 the Dangerous Drugs (Supply to Addicts) Regulations of $1968,5^{58}$ and the Dangerous Drugs (Notification of Addicts)

49. Interdepartmental Comm. on Drug Addiction, Report 9 (Nov. 29, 1960) (Sir W. Russell Brain chaired the committee.) [hereinafter the Brain Committee RePORT].

50. G. Stimson \& E. Oppenheimer, supra note 26, at 44-45.

51. Spear, supra note 30 , at $245,247$.

52. G. Stimson \& E. Oppenheimer, supra note 26 , at 47.

53. The term "grey" market is sometimes used to refer to an illegal supply of pharmaceutical drugs which derive from doctors" prescriptions in contrast to a "black" market which refers to illegally imported drugs.

54. G. Stimson \& E. Oppenheimer, supra note 26 , at 47.

55. Id. at 46-47.

56. Brain Committee Report, supra note 49 , at 8 .

57. Dangerous Drugs Act, 1967, ch. 82.

58. Dangerous Drugs (Supply to Addicts) Regulations, S.I. 1968, No. 416. 
Regulations of $1968 .{ }^{59}$ Thus ended the Rolleston Era and began the Clinic Era.

By the autumn of 1968, fifteen clinics were established in London, and an additional twenty-four were opened in other parts of England and Wales. ${ }^{60}$ Although the facilities available varied, every clinic provided hospital-based services to outpatient addicts. The University College Hospital Drug Dependency Clinic was typical of London clinics operating at the beginning of the Clinic Era:

The U.C.H. Clinic, situated a few minutes walk north of Tottenham Court Road, where London's West End fades away to be replaced by small businesses, workshops, and residential housing, had its own rooms in the National Temperance Hospital, with a separate street entrance for patients. Staff entered through the main hospital. Entering the Clinic from the street were a few steps up to a waiting area, which had wooden seating on three sides. The visitor may have found six or seven waiting patients. Just opposite the street door was a cubicle for the porter, who took details of arriving patients. Beside the porter was a corridor leading to the consulting rooms, and a door into the secretaries' office... In 1975, this Clinic was under the charge of a part-time consultant, helped by another senior psychiatrist, working a total of six half-day sessions a week. There were two full-time social workers, and a part-time clinical psychologist. . . The Clinic opened for three half-days a week, and one evening. During 1974, a total of 328 addict patients were treated by the Clinic. . . In addition, and this was unusual for many clinics, twenty-eight non-opiate-using patients were seen. Most of the patients seen were aged in their twenties, and three out of four were men. ${ }^{61}$

In the early years, most addict patients received a prescription for some kind of drug. The choice of drug was at the discretion of the consultant psychiatrist responsible for the Clinic and this varied among clinics and within different parts of the country. Initially, many clinic-based doctors continued to prescribe heroin on a regular basis to addicts but in reduced quantities compared with the pre-clinic levels of private doctors. ${ }^{62}$

In the early 1970's, doctors began to prescribe methadone rather than heroin and to reduce the dosages prescribed. By the end of the decade, consultants in charge of the London treatment centers agreed among themselves to two major changes in policy: first, to prescribe injectable heroin or methadone to neither new patients nor former patients returning from periods of abstinence; second, to accept patients only from a limited geographic "catchment" area. ${ }^{63}$

In 1964, the Interdepartmental Committee on Drug Addiction was reconvened in response to the growing number of persons addicted to dangerous drugs. ${ }^{64}$ Six aspects of the "new situation" to which the Committee was to respond are listed in its report: first, the growth in the

59. Dangerous Drugs (Notification of Addicts) Regulations, S.I. 1968, No. 136.

60. G. Stimson \& E. Oppenheimer, supra note 26 , at 81 .

61. Id. at 95 .

62. Johnson, How Much Heroin Maintenance (Containment) in Britain?, 12 INT'L J. Addictions 36198 (1977).

63. See generally $\mathrm{H}$. Spear, British Experience in the Management of Opiate Dependence (1982).

64. See generally Brain Committee Report, supra note 49. 
number of known heroin addicts between the years 1959 and 1964; second, the growth in the number of cocaine addicts over the same period; third, the tendency for new addicts to be non-therapeutic in origin; fourth, the change in age distribution from older to younger users; fifth, the widespread use of heroin in medical treatment; and sixth, the focus of the spread of addiction on London and the larger cities. ${ }^{65}$ The Committee's proposals to curtail the spread of addiction reflected its perception that the supply of drugs was the major cause of the problem. In particular, the Committee believed that the escalating addiction in Britain resulted from an increasing grey market in pharmaceutical drugs caused by an over-prescribing by a small number of doctors. ${ }^{66}$ Thus, the Committee's subsidiary aims were directed at controlling the prescribing powers of doctors in order to achieve the broad aim of checking the spread of addiction.

The Committee's proposals were far more successful in achieving the subsidiary aims than they were in achieving the broad aim. During the 1970's and 1980's the number of known addicts has increased dramatically. In 1974, a total of 1,437 addicts were recorded as receiving notifiable drugs at January 1 of that year. ${ }^{67}$ By $1983,5,850$ addicts were recorded as receiving notifiable drugs, more than four times the number recorded ten years earlier. 68 Other indices of the incidence of drug use point to similar increases. The quantity of heroin seized increased from 2.8 kilograms in 1974 to a provisional total of 299 kilograms in 1984.69 The number of persons found guilty or cautioned for drug offenses increased from 12,532 in 1974 to 23,300 in $1983 .{ }^{70}$

This evidence shows that the clinic system did not reduce the incidence of addiction in absolute terms from earlier levels. Because the population remained fairly static over this period, ${ }^{71}$ this evidence suggests also that the rate of addiction as a percentage of the population increased. While it is possible to argue that the rate is lower than it might have been under an alternative system, it is nonetheless clear that the impact of the clinic system has not been sufficient to justify its continuation in Britain as the central mechanism of control against drug abuse.

Despite the failure of the Committee's proposals to curtail the spread of addiction, it was fairly successful in achieving the subsidiary aims. In particular, both the requirement that doctors who wished to prescribe heroin or cocaine to addicts must be licensed by the Home Office, and the provision of an alternative licit source of supply through drug treatment centers almost instantaneously reduced the problem of over-prescribing by private doctors and quelled the existing grey market in pharmaceutical heroin. Additionally,

\footnotetext{
65. Id. at 5 .

66. Id.

67. Home Office, Tackling Drug Misuse: A Summary of the Government's Strategy 5 (1985).

68. Id

69. Id.

70. Id.

71. Id.
} 
the system of notification of addicts substantially increased the information available on the epidemiology of addiction.

In two other respects, however, the subsidiary aims of the Committee's proposals were not as successfully attained. First, the Committee's desire for a critical balance between the availability and restriction of licit drug supplies was not realized. In describing the need for such a balance, the Committee stated:

If there is insufficient control it may lead to the spread of addiction-as is happening at present. If, on the other hand, the restrictions are so severe as to prevent or seriously discourage the addict from obtaining any supplies from legitimate sources it may lead to the development of a [sic] organized illicit traffic. ${ }^{72}$

That the statistics on the number of addicts and seizures of drugs show both a spread of addiction and an increase in illicit traffic, ${ }^{73}$ suggests that the balance between availability and restriction (sometimes referred to as "controlled availability") ${ }^{74}$ has not been struck.

Additionally, the subsidiary aim of creating a clinic system was only partly achieved. The number of hospital-based treatment centers failed to expand much beyond the number established during the first year of operation of the system. ${ }^{75}$ Consequently, a large proportion of addicts in the country had no access to a clinic and, therefore, were not under clinic treatment or control.

Thus, the Committee's proposals failed to create a successful system of treatment and control in Britain in the way envisaged. This is not to say that it has had no impact on either the demand or supply of drugs, but rather that its success has been too limited and insufficient to affect the spread of addiction in the country. The limited success of the system is almost certainly a combination of implementation failure and theory failure. Implementation failure comprises mainly the narrow expansion of the Clinic System which resulted in only a small proportion of addicts being covered by its provisions. Theory failure almost certainly occurred in relation to the exclusive focus of the Brain Committee on the supply of drugs as a factor in the creation of addiction at the expense of a proper consideration of the impact of demand.

\section{The Present Era}

The Present Era commenced in the mid-1970's when the first seeds of doubt were sown about the effectiveness of the Clinic System proposals. During this time, the primary goal of the clinics shifted from a combination of treatment and control to a predominantly treatment oriented approach, marking a dramatic rebellion among the medical profession against the principles of the Brain Committee. Doctors began prescribing oral methadone in place of injectable heroin, and their treatment changed from

72. Brain Committee RePort, supra note 49 , at 7.

73. HoMe OfFice, supra note 67.

74. "Controlled availability" refers to a policy of providing licit supplies of opioids to addicts under controlled conditions.

75. Department of Health and Social Security, Treatment and Rehabilitation: Report of the Advisory Council on the Misuse of Drugs (1982). 
maintenance prescribing to a short rapid reduction course. ${ }^{76}$ This shift was prompted in part by a growing disbelief in the efficacy of "competitive prescribing" 77 as a means of controlling addiction and the black market in illicit drugs, and in part by a practical need to generate higher turnover rates within the clinics. ${ }^{78}$

The impetus for change in the 1980's was not confined to the growing disillusionment among clinic doctors. Substantial increases in all the indicators of the number of addicts within the country showed clearly that addiction was not being contained but was in fact spreading. In addition, changes in where drugs could be obtained and how they were used caused rising concern among officials. Whereas in the early 1960's most addicts obtained their drugs in London or in one or two other big cities, in the 1980's heroin and other dangerous drugs could be purchased in most parts of the country. ${ }^{79}$ In the 1960 's, intravenous injection was the most common form of administration. By the early 1980's the most common forms were by inhalation (chasing the dragon) and by sniffing (snorting) ${ }^{80}$ The change to non-injectable administration weakened social controls by releasing some of the inhibitions associated with intravenous injection which might have prevented potential novitiate users from experimenting with the drug.

In response to these changes and to the government's concern about the reluctance of the medical profession to enter into a combined treatment and control contract, ${ }^{81}$ in 1985 the Home Office published a booklet entitled Tackling Drug Misuse, which outlined official policy for dealing with drug addiction. ${ }^{82}$ Much less emphasis was placed on the role of the medical profession as a course of official control. Instead the Home Office booklet emphasized: (1) improving international cooperation to limit the cultivation of drugs abroad; (2) improving the efficiency of Customs and Excise staff by increasing their numbers and redefining their priorities; (3) improving ordinary policing in the country by strengthening special drug squads; (4) increasing the severity of penalties imposed on drug offenders in order to deter drug use; and (5) controlling the storage and distribution of licit drugs by enhancing record keeping methods and improving physical security. ${ }^{83}$

The provisions outlined in the booklet reveal a substantial modification in policy over previous years. They represent a more diverse and wide-ranging approach to the problem of drug addiction than at any previous time.

76. See generally Spear, supra note 63.

77. "Competitive prescribing" refers to a policy of attempting to undercut the black market by providing licit supplies of opioids.

78. See generally Edwards, supra note 14.

79. See generally Stimson, supra note 9 , at 477-88

80. Id.

81. A "combined treatment and control contract" refers to a policy of treating addicts in a way which will not only benefit the individual addict but also ameliorate some of the social problems of addiction. In practice, this means prescribing drugs of addiction to addicts to diminish their use of the black market and to reduce drug-related crime.

82. See generally Hоме OfFice, supra note 67.

83. Id. at 7-23. 
Moreover, they mark a shift away from a limited legal or medical response, undermining the usefulness of the terms "medicalization" 84 and "criminalization" 85 in explaining drugs policy. Finally, the publication of the booklet represents a new politicization of drugs policy whereby proposals for dealing with drugs problems become bona fide political topics. ${ }^{86}$

Further, a report published in 1984 by the Department of Health and Social Services (DHSS) proposed a new role for general practitioners (GP's) ${ }^{87}$ The major role for GP's under the Clinic System was largely one of gatekeeper in that they were responsible for referring their addict-patients to the clinics for specialist treatment. Although GP's were still discouraged from long term prescribing, they were now encouraged to offer detoxification services to addicts. ${ }^{88}$ An additional change in the treatment of addicts is the government's program to encourage voluntary bodies to offer addicts a wide range of self-help and rehabilitation services. To this end, the DHSS has made available considerable funds as an incentive to establish such services. ${ }^{89}$

The recent onset of AIDS in the 1980's is likely to affect radically the British approach to drug addiction. In particular, it is likely to reintroduce the medical profession as the major thrust of the British System in the future. Because intravenous drug users are one of the highest risk groups in contracting the AIDS virus, the growing AIDS epidemic prompted the Social Services Secretary to launch a pilot scheme in four cities in Britain. The program provides street addicts with free needles in exchange for used needles. ${ }^{90}$ This move was supported by both the British Medical Association and the Home Office.

Dr. Philip Connell, Chairman of the Home Office Advisory Committee on the Misuse of Drugs, and author of the official guidelines for general practitioners, recently argued that the cautious and moderate approach advocated by the official guidelines is now inappropriate in light of the arrival of AIDS. ${ }^{91}$ He proposes abandonment of the policy that doctors only accept addicts for treatment if they promise to withdraw and are willing to accept rapidly reducing dosages of methadone. In order to curb the spread of AIDS, Dr. Connell suggests that regular users should be given free needles and free supplies of methadone or heroin indefinitely if they need them. ${ }^{92}$ Consultants in charge of the clinics are beginning to accept this line of argument. ${ }^{93} \mathrm{In}$

84. See infra notes 94,95 , and accompanying text.

85. Id.

86. Stimson, supra note 9 , at 484 . See also Smart, supra note 15 , at 32.

87. See generally Department of Health \& Social Services, Guidelines of Good Clinical Practice in the Treatment of Drug Misuse (1984) (a report by the Medical Working Group on Drug Dependence).

88. Id. at 7,9 .

89. See generally Home OfFice, supra note 67.

90. Free . Needles for Addicts to Curb AIDS Spread, The Guardian, Dec. 19, 1986, at 28, col. 1

91. Tough Line with Heroin Addicts Working as Home Office Considers Easing Rules, The Guardian, May 30,1987 , at 2 , col. 4 .

92. Id.

93. Id. 
terms of the development of British drugs policy, this move is of great importance and effectively overturns most of the informal policy agreements among clinic consultants which have been in operation since the early 1970's.

\section{III}

\section{Conceptualizing the British Approach}

To understand the British System, one must step back and look beyond the key stages of its history to the major movements and themes underlying its development. One approach that has been used frequently in the literature draws upon the concepts of medicalization and criminalization.94 Medicalization is the tendency for a country to deal with a form of deviance as if it were a medical problem, and criminalization is the tendency to deal with such deviance as if it were a criminal problem. One of the virtues of the British System is its tendency to medicalize the problem of addiction by treating addicts as sick rather than to criminalize the problem by treating them as criminals. ${ }^{95}$ It is nonetheless misleading to describe the British System as solely one of medicalization.

During the early years of the Rolleston Era, ${ }^{96}$ it was clear that the predominant approach to addiction in Britain was to treat the addict as a sick person who was best dealt with by the medical profession. Addiction was seen as a disease which generated an overwhelming craving for a particular drug, a craving over which the person afflicted had little control. Yet, in addition to the medical response, the 1920 and 1923 Dangerous Drugs Acts contained various legal controls on the supply and distribution of opioids. ${ }^{97}$ During the Clinic Era, the official conception of addiction was also medical rather than criminal in nature. The Report of the Second Brain Committee explicitly reaffirmed the disease model of addiction and argued that addiction was predominantly a problem to be dealt with by doctors. ${ }^{98}$ At the same time, however, the government substantially revised its drug laws, resulting in the 1971 Misuse of Drugs Act which made the possession and distribution of a wide range of controlled drugs an offense punishable by imprisonment of up to fourteen years. ${ }^{99}$

The concept of medicalization has also been criticized because it implies that the social problem of addiction arises independently of the medical profession. ${ }^{100}$ In "Social Policy and Drug Addition: A Critical Study of Policy Development," Smart argues that the definition of addiction as a social problem is itself a product of medical knowledge and, as such, the definition

94. See, e.g., P. Conrad \& J. Schneider, Deviance and Medicalization: From Badness to Sickness $110(1980)$.

95. E. Shur, supra note 11 , at 205.

96. See supra notes $26-41$ and accompanying text.

97. See supra note 5 and accompanying text.

98. See supra notes 64-66 and accompanying text.

99. Misuse of Drugs Act, 1971, $\S 25$, ch. 38 .

100. Smart, Social Policy and Drug Addiction: A Critical Study of Policy Development, 79 BRrT. J. Addiction $31-39$ (1984). 
implies the need for medical treatment. ${ }^{101}$ The same argument is applied to alcoholism and homosexuality.

Smart presents an alternative conceptualization which stresses the importance of rational scientific knowledge in the development of drugs policy. She argues that the definition of addiction as a social problem arose initially out of the development of the concept of public health which, in turn, arose from the scientific conceptualization of society as an organic entity which could be afflicted by disease. ${ }^{102}$ The body of rational knowledge at any point in time is a source from which problems and their solutions may arise. To devise solutions, policy makers inevitably draw upon this body of knowledge. Smart argues that the Second Brain Committee Report can be understood in terms of application of rational scientific knowledge. The medical knowledge base had changed little since the beginning of the century, and concepts relating to public health and disease extended from the Rolleston Report to the time of the Brain Report. However, in other respects, rational scientific knowledge had progressed and new technologies were becoming available. These technologies included the development and use of methadone in the treatment of addiction, urine testing, more sophisticated methods of collecting information, more rational methods of monitoring drug records, and the establishment of a Drugs Inspectorate. Smart concludes that the Brain proposals do not reflect a major shift in treatment paradigms, but rather a change in available technology. ${ }^{103}$

Smart's analysis is, however, insufficiently general to be useful as a grand theory and is insufficiently detailed to explain satisfactorily specific policy developments. Because the account leaves too many questions unanswered, it prevents the approach from being adopted by others or applied to other events with any degree of confidence. Nevertheless, there are a number of ideas which might be useful in the development of policy analysis.

The proposition that problems are identified and solutions are derived from the current stock of available knowledge which includes both empirical fact and currently fashionable theory is an attractive one. This conceptualization can be applied with some success to twentieth century drugs policy. At the time of the Rolleston Committee Report, the problem identified was an incongruence between recent legislative changes and methods used by the medical professions in the treatment of addiction. ${ }^{104}$ The solution was sought in current medical knowledge which reaffirmed that addiction was a disease and that a medical response was thus justified. The problem identified by the Second Brain Committee was the increase in number, and change in characteristics, of new addicts known to the Home Office. The response devised was based upon current empirical data and an

101. Id. at $32-34$.

102. Id at 34 .

103. Id. at 38 .

104. See supra notes 22-24 and accompanying text. 
acceptable theory of the cause of the spread of addiction. ${ }^{105}$ Scientific knowledge continued to support the notion of addiction as a disease. The Committee's solution, therefore, sought to deal with the perceived cause of the problem (the doctors) and also to maintain the role of the doctors in the treatment of addiction. The complexity of the result matched the complexity of the problem.

A knowledge-based conceptualization of drugs policies is perhaps more useful in attempting to explain the diversity of methods employed to regulate drug abuse in Britain in the 1980's. Current knowledge about the supply and distribution of heroin and other opioids is greater than it has ever been because intelligence from the police and Customs and Excise, and international cooperation have painted a comprehensive picture of worldwide drug movements. ${ }^{106}$ Additionally, the system of notification and the detailed recording of the type and purity of drugs purchased on the black market expanded knowledge on the number and type of addicts in Britain. ${ }^{107}$ The Home Office's Tackling Drug Misuse is far more complex than any earlier policy document in terms of the number of problems identified and solutions offered. ${ }^{108}$ Similarly, recent educational and prevention programs coupled with government encouragement and support for voluntary agencies suggest the presence of not a simple medicalization or criminalization of the problem but a multi-fronted approach. Moreover, the possible reversal of prescribing policy in the clinics in response to recent knowledge about the spread of AIDS suggests a pragmatic and knowledge-based approach.

One consequence of a broad-based utilitarian policy on drug abuse is that philosophical and ideological issues concerning the rationality and morality of different policies are subordinated to the dominant aim of coming up with something that works. It is likely that such a system will become complex and change rapidly as strategies come and go out of fashion.

\section{Conclusion}

There are many advantages associated with a pragmatic approach which defines problems and seeks answers in the currently available and fashionable stock of knowledge. There is no need to wrestle with broader issues relating to drugs policy, such as whether there should be legal controls of certain drugs. There are also many disadvantages, however, with such policies which need to be considered by policy makers before adopting a pragmatic approach. In particular, it is important to consider the messages about drug

105. See id.

106. See Home OfFICE, supra note 67.

107. A "system of notification" is a system whereby doctors are legally required to state, in the form of regular returns to the Home Office, the names of any patients who have approached them during a specified period (whether or not treatment was offered) whom they know, or suspect, to be using specific classes of controlled drugs. See Home OfFice, supra note 67, at 5.

108. Id. 
use which are conveyed not only by each new policy, but also by the changes in policy. What impact has the recent British policy of supplying free needles to addicts to control the spread of AIDS had on nonusers and potential users who had previously received the message that needles were restricted because intravenous injection was dangerous? What are the consequences of a sequence of policy decisions which first made opioids readily available to users, then dramatically restricted their supply, and then made them available again? It would seem that pragmatic and rapidly changing drugs policies create a danger of mixing messages about drug use to both drug users and nonusers. The failure of the government to develop a philosophically and morally sound system of controlling addiction and its associated problems could have consequences for the spread of drug use in a country which might not be responsive to further dosages of pragmatism. 